\title{
CULTURA DE EMPRESA: UMA NOVA DINÂMICA ORGANIZACIONAL*
}

José M. Amado Mendes

\section{INTRODUÇÃO}

Nas últimas décadas, o conceito de cultura tem vindo a adquirir um âmbito muito mais vasto que o tradicional. Este, como é sabido, apenas contemplava a cultura de tipo erudito, isto é, literária, filosófica ou artística. Para isso contribuíram ciências como a antropologia, a etnologia e a sociologia, mas também as novas concepções do homem e da vida, estudadas e veiculadas pela história. Assim, falamos hoje de cultura de povos primitivos, de cultura operária, de cultura industrial ou de cultura material. Em alguns casos, o adjectivo cultural é mesmo utilizado para caracterizar toda uma civilização, como sucede com o recente livro publicado em França, da autoria de Fumarioli, intitulado precisamente L'État culturel. Essai sur une religion moderne ${ }^{1}$. Neste contexto, caracterizado por uma certa revalorização e vulgarização do cultural - e, simultaneamente, pelo reforço do papel desempenhado pela empresa -, não surpreende que o interesse pela temática cultura de empresa tenha vindo a aumentar, de forma notória. Já se afirmou não existir hoje discurso sobre a empresa que não fale de cultura. Daí o assunto ter entrado na ordem do dia de publicações, especializadas ou mesmo de carácter mais genérico - como periódicos ou semanários -, conferências, seminários, ensino e investigação. Parece-me, assim, estar suficientemente justificada a inclusão do tema nestas Jornadas, visto tratar-se, como veremos oportunamente, de um instrumento fundamental para uma gestão moderna e actualizada.

\section{DEFINIÇÃO E ORIGENS DA CULTURA DE EMPRESA}

Poder-se-á, entretanto, perguntar: que deve entender-se por cultura de empresa? Como têm sido dadas diversas definições, não poderão ser todas anali- 
sadas no âmbito desta comunicação. Deixando de parte algumas definições mais complexas $^{2}$, vejamos os seguintes exemplos:

a) Cultura de empresa é «a programação colectiva do espírito humano que permite distinguir os membros de uma categoria de homens em relação a uma outra» (D. Bullinger e G. Hofstede, 1987:27).

b) Ou, segundo outra definição:

«A empresa produz sinais. Estes são o resultado de uma multidão de moléculas (memória colectiva, relações sociais, investimentos, campanhas de promoção, formação permanente, ambiente local, etc.). Todas elas formam a "cultura de empresa" $»^{3}$.

c) De forma ainda mais simples, já se afirmou ser a cultura «uma maneira de pensar a organização, hoje» (M. Thévenet, 1984:16).

Nas três definições apresentadas, sublinham-se sobretudo, respectivamente, a identidade de determinado grupo humano, os sinais produzidos e acções desenvolvidas e a perspectiva pela qual se foca a organização.

Relativamente às origens da cultura de empresa, acrescente- se que elas são tão antigas como as próprias organizações a que dizem respeito. Assim, a «febre» da cultura de empresa, que caracteriza a nossa época, se constitui novidade, não é propriamente quanto às origens do fenómeno, mas sim no que respeita à consciencialização que dele tem vindo a adquirir-se e, inclusive, no que toca à reflexão, teórico-prática, a que estamos a assistir. Mesmo hoje, admite-se que só conhecemos cerca de $10 \%$ da cultura de cada empresa. Todavia, até há relativamente pouco tempo, o fenómeno passava quase completamente despercebido, um pouco como o exemplo dado por Tom Peters - co-autor da Paixão pela excelência ${ }^{4}$-, ao notar que o seu entrevistador - como ele próprio - , não obstante vestir as calças todos os dias de manhã, não conseguia recordar-se que perna vestia primeiro ${ }^{5}$.

Mas, como explicar esta redobrada atenção à cultura de empresa, nas últimas décadas?

Alguns autores, além dos aspectos genéricos que já referi na introdução, apontam as seguintes justificações:

- uma certa contestação às empresas, por exemplo, nos Estados Unidos e em França, a qual levou ao reconhecimento de que, naquelas, a realidade social coexistia com a realidade económica (M. Thévenet, 1986: 13);

- a falência do Estado-Providência terá levado também as pessoas a voltarem-se para a empresa (L. Reto e A. Lopes, 1990:18);

- a verificação de que as culturas mais tradicionais - de pendor aristocrático, uma, e operário, outra - não esgotavam a compreensão dos factores culturais e dos respectivos grupos humanos, ligados às organizações; 
- a transformação do ambiente humano e social, no que se refere a uma certa elevação dos recursos humanos, devido aos seguintes factores:

- rendimento real que, em certos casos, triplicou;

— educação;

— informação;

- atitude crítica;

— protecção legal (O. Gélinier, 1990: 222).

Em suma: novos ambientes - económicos, sociais e culturais - e novas achegas, trazidas pelas ciências humanas e sociais, favoreceram $\mathrm{o}$ aparecimento e a sistematização de uma nova disciplina, não obstante o respectivo objecto já ter décadas ou mesmo séculos de existência.

\section{FACTORES E COMPONENTES DA CULTURA ORGANIZACIONAL}

São múltiplos os factores que integram a cultura de empresa. Entre eles distinguem-se: símbolos, mitos, ritos, valores, imagens, identidade, fundadores e/ou outros líderes carismáticos ou marcantes, histórias e/ou estórias, etc. Entre muitos outros exemplos que poderia indicar, chamo a atenção para os seguintes: certos tipos de vestuário usado pelo pessoal; troféus comemorativos; prémios; determinadas cerimónias, evocativas de datas assinaláveis para a organização e material informativo. No que toca aos fundadores, não raro surgem como autênticas figuras carismáticas, já que, para além de terem dado origem à organização, em muitos casos criaram igualmente uma certa cultura, que perdurará durante a vida daquela. É por isso que continuamos a associar, por exemplo, José Ferreira Pinto Basto à Vista Alegre, José dos Santos Barosa à Santos Barosa ou Alfredo da Silva à ex-CUF (Barreiro). Casos análogos se verificam noutros países. Em França, embora a Renault tenha adquirido a Berliet, o fundador desta, Marius Berliet, continua a ocupar um lugar de destaque no seio da organização, inclusive como patrono de uma Associação (sediada em Lyon) que preserva e estuda a respectiva memória e que tem, precisamente, o seu nome ${ }^{6}$. Aliás, esse papel - decisivo ou mesmo determinante - de certos líderes e, sobretudo, dos fundadores, encontra-se patente até em certos pormenores biográficos. Por exemplo, Henri Nestlé é referido como farmacêutico, mas também homem de negócios; de André Citroën, por seu turno, diz-se que não sonhava senão com a técnica ${ }^{7}$.

\section{HISTÓRIA, IDENTIDADE E CULTURA DE EMPRESA}

Até há algumas décadas atrás, existia uma certa relação de conflito - ou, pelo menos, de indiferença - entre história e empresa. $O$ historiador, muito 
mais preocupado com organizações mais tradicionais e amplamente consagradas - Estado, Igreja, Escola, Família e Instituição Militar —, encontrava-se pouco sensibilizado para o estudo da empresa. Por sua vez, o empresário, ainda muito cioso do secretismo dos "negócios", via o historiador — ou mesmo outros cientistas sociais - como um intruso, raramente lhe franqueando os arquivos, a não ser para estudos por ele solicitados, geralmente com intuitos comemoracionistas, senão mesmo laudatórios. Entre nós, o panorama que acaba de ser descrito, infelizmente, ainda não se encontra completamente superado. Todavia, a exemplo do que tem vindo a suceder em alguns países - entre os quais, Grã-Bretanha, França e Estados Unidos - começa a notar-se uma maior abertura, de parte a parte. Em alguns casos, fazem-se histórias, organizam-se arquivos e instalam-se museus de empresa. Como tenho vindo a sublinhar noutros trabalhos ${ }^{8}$, a história, pelo menos dos últimos dois séculos, não pode deixar de se debruçar sobre as empresas, como importantíssimos estudos de caso que são. Por sua vez, a empresa encontrará na sua história uma prestimosa colaboração, quer no que toca a um melhor conhecimento do seu passado - e, consequentemente, como reforço da sua própria identidade - , quer no que respeita à compreensão do contexto em que a mesma se insere e actua, a nível local/regional, nacional e internacional. Daí que se deva fazer um considerável esforço com vista a, por um lado, levar a história a "mergulhar" na empresa e, por outro, a induzir a empresa a recorrer, mais frequentemente, à história.

Como é sabido, a história da empresa faz intervir três tipos de actores:

1) o empresário e/ou o gestor;

2) os assalariados/colaboradores;

3) o historiador (A. Beltran e M. Ruffat, 1991:38).

Os estudos históricos das empresas permitirão esclarecer, entre outros, os seguintes assuntos, aliás de importância fundamental, quando perspectivados diacronicamente:

- evolução das estruturas e da tecnologia;

- políticas e estratégias de gestão;

- processos de fusão, caso existam;

- as grandes datas;

- o ambiente;

- os homens;

— a relação e inserção no mercado ("marketing", publicidade, etc.).

Estes e outros aspectos foram por mim estudados, em obra recentemente vinda a lume, sobre uma empresa vidreira da Marinha Grande 9 .

O estudo da história - das nações, dos povos e das organizações - é o meio mais adequado de reforçar e consolidar a respectiva identidade. Esta pode ser definida como «um conjunto de características interdependentes da organização que the conferem a sua especificidade, estabilidade e a sua coerência» ${ }^{10}$. 
A identidade, como sub-tema no âmbito da cultura de empresa, tem vindo a despertar crescente atenção, como, aliás, já havia sucedido no que se reporta à identidade individual, do ponto de vista da Psicologia. É que, estudar a identidade da empresa não visa propriamente satisfazer uma curiosidade nem é, tão-pouco, uma questão exclusivamente académica. Por ela passa, efectivamente, muito da motivação e do empenho do pessoal envolvido em determinada organização, ao mesmo tempo que ajuda a concretizar projectos e a compreender os principais elos da própria cultura de empresa. Wally Olins, num importante trabalho há pouco publicado, exactamente intitulado Identité d'entreprise, destaca:

«Para que uma organização se possa manter viva, é preciso que os seus membros tenham a percepção clara do seu fim e que lhes adiram com força. Não há identidade institucional sem projecto e coesão» (O. Olins, 1991:7).

A identidade resulta da combinação dos seguintes factores:

1) os produtos e serviços que a empresa fabrica e/ou vende;

2) o meio na qual ela fabrica e vende;

3) as informações que ela veicula para publicitar os seus produtos e as suas actividades;

4) finalmente, a forma como os seus membros se comportam, no interior como no exterior da organização ${ }^{11}$.

Concretizando alguns destes aspectos o autor supracitado esclarece:

«Numa empresa em que o produto tem primazia, ele será naturalmente a pedra angular da identidade. A sociedade Jaguar identifica-se assim com o automóvel que ela fabrica - a sua velocidade, o seu preço, o seu conforto interior, a sua fama, o barulho do motor, a forma como ele se desloca, trava e volta a arrancar. Estes atributos do produto condicionam em larga medida a identidade de toda a empresa» ${ }^{12}$.

Os próprios factores ambientais são importantes para as firmas prestigiarem os seus produtos. A cultura operária e/ou empresarial, o saber-fazer, por vezes secular, o carinho com que as pessoas exercem certa actividade constituem factores de identidade que não podem ser olvidados. Casos como o Vale do Ave (têxtil algodoeira), a zona da Serra da Estrela (lanifícios) e a Marinha Grande (vidros) são sobejamente conhecidos.

O reforço da identidade ajuda a programar e a desenvolver a estratégia da empresa, actuando nas seguintes vertentes:

— imagem que a empresa deseja transmitir de si própria, ou seja, a coerência;

- o campo que deseja simbolizar, colocando a tónica no simbólico;

- o desejo de diferenciação no mercado, cuidando-se do posicionamento da empresa ${ }^{13}$. 


\section{A CULTURA DE EMPRESA COMO INSTRUMENTO DE GESTÃO}

O estudo da cultura de empresa constitui apenas um primeiro passo, ao qual se deve seguir a sua utilização. Portanto, ao gestor não interessa, somente, saber muito sobre cultura de empresa. Esse saber, apesar de importante, adquirirá um novo significado se for aplicado, numa gestão pela cultura. Segundo já foi afirmado por um especialista destas questões, para que a moda (cultura de empresa) se desenvolva, são necessárias duas ajudas:

1. a operacionalização, ou seja, é necessário transformar em utensílio de intervenção, de diagnóstico e de acção o conteúdo teórico que a rodeia;

$2 .^{\circ}$ que haja modelos a imitar, como se revelam em Le Prix d'exellence, onde se defende uma cultura forte ${ }^{14}$.

A cultura de empresa deverá ter uma função globalizante, pois apresenta as seguintes características:

1. é um "cimento" que liga o conjunto dos elementos da empresa;

2. é um exemplo fundamental do que se passa;

3. é o produto de uma história e não de um instante;

4. é um património de saber-fazer;

5. é um modo de descrever a organização;

6. ajuda a transmitir uma imagem favorável da empresa, o que representa, por si mesmo, uma certa segurança quanto ao futuro. Na construção e transmissão dessa imagem intervêm sinais materiais visíveis, manifestações de cada empresa, atitudes e sentimentos;

7. é uma linha ideal de acção, em resposta à palavra de ordem, «procurai cultura», que tem estado em voga.

A cultura de empresa tem um lugar privilegiado em muitas circunstâncias da vida empresarial, como, por exemplo, nas seguintes:

- recrutamento do pessoal;

- formação, a diversos níveis;

- motivação e empenhamento (muito importante);

- partilha das responsabilidades. Passa-se da lógica da obediência à lógica da responsabilidade;

- identificação com as estratégias e fins estabelecidos;

- comunicação.

Sem menosprezar os outros aspectos - todos eles da maior relevância -, vejamos, um pouco mais de perto, a problemática da motivação e da comunicação. Quanto àquela, já foi sublinhado:

«O líder é hoje um dirigente que se interessa pelos valores em mutação, pelas motivações do pessoal. É um dramaturgo, carismático, mag- 
nético, mesmo dominador, abrangendo tudo e todos com a atenção e, sobretudo, mobilizador de energias» (A. Michalowska, 1988:35).

Quanto à comunicação, o empresário/gestor começa a ser visto como vedeta mediática. «Cada vez mais - admite-se hoje - os gerentes se transformam em gestores da comunicação» ${ }^{15}$.

Entre as numerosas modalidades de comunicação, ressalta cada vez mais a das publicações da própria empresa, nas quais a respectiva cultura deverá ter um lugar proeminente. Um livro, recentemente publicado em França, intitula-se, precisamente, Créez vos publications d'entreprise ${ }^{16}$.

A comunicação passa também, obviamente, pelo turismo industrial e pela museologia de empresa, que tem vindo a adquirir uma importância cada vez mais destacada ${ }^{17}$.

Para não me alongar demasiado, eu concluiria com uma passagem da obra supracitada de W. Olins, sobre identidade de empresa:

«Ao fim de contas, evidentemente que será o poder económico o vencedor. Mas o poder económico repousa cada vez mais num poder de essência moral, estética e cultural. São as organizações que souberem reunir e utilizar o conjunto destas forças que dominarão o mundo no século XXI» ${ }^{18}$.

\section{NOTAS}

* O texto que ora se publica, anotado, foi inicialmente apresentado através de duas comunicações, em Viseu (às I Jornadas de Gestão Geral e III de Recursos Humanos, do Curso de Gestão e Desenvolvimento Social do Centro Regional de Viseu da Universidade Católica Portuguesa, em 15.05.1992) e no Porto (às Jornadas de Economia da Universidade Lusíada, em 22.05.1992).

1. Marc Fumarioli, L'État culturel. Essai sur une religion moderne, Paris, Ed. Fallois, 1991.

2. Como a que se segue: «A cultura organizacional é o conjunto das hipoteses (assunções) de base que um dado grupo inventou, descobertas ou desenvolvidas de modo a fazer face aos seus problemas de adaptação externa e de integração interna, e que têm suficiente cotação para serem consideradas como válidas e ensinadas aos novos como sendo a forma justa de pensar, perceber e sentir perante esses problemas» (Schein, «Comming to a new awareness of organizational culture», MIT, Sloam Management Review, Winter, 1984, apud Maurice Thévenet, «La culture d'entreprise en neuf questions», Revue Française de Gestion, n. ${ }^{\circ} 47-48,1984$, p.12). (Tradução minha, como em casos análogos, de citações a partir de língua estrangeira).

3. «Le ticket-choc de la culture d'entreprise», Autrement [número monográfico, sob o título Le culte d'entreprise. Mutations, valeurs, cultures], série "Mutations", n. ${ }^{\circ} 100,1988$, p. 41.

4. Tom Peters e Nancy Austin, A paixão pela excelência (trad. do inglês), Lisboa Pensamento-Editores Livreiros, 1988. 
5. «Le gourou. Entretien avec Tom Peters», Autrement, n. ${ }^{\circ} 100,1988$, p. 49.

6. Trata-se da «Fondation de l'Automobile Marius Berliet", cujo endereço e: 39, avenue d'Esquirol - 69003 Lyon - FRANCE.

7. Maurice Thévenet, «Voyage d'un "entreprenaute" dans la tribu. Mode d'emploi à usage de diagnostic. Quels sont les outils d'entification d'une culture d'entreprise?», Autrement, n. ${ }^{\circ} 100,1988$, p.44.

8. José M. Amado Mendes (col. de Manuel Ferreira Rodrigues), Santos Barosa - 100 anos no vidro, 1889-1989, Marinha Grande, Santos Barosa - Vidros, SA, 1992; "A história na empresa e a empresa na história», no prelo (artigo que será publicado na obra de homenagem ao Prof. Borges de Macedo).

9. Cfr. supra, nota 8.

10. J. P. Larçon e R. Reiter, Structures de pouvoir et identité de l'entreprise, Paris, Ed. Fernand Nathan, 1979, p.43, apud A. Lopes e L. Reto, Identidade da empresa e gestão pela cultura, p. 38-39.

11. Wally Olins, Identité d'entreprise. Pour rendre la stratégie d'entreprise visible (trad. do inglês), Paris, Inter Éditions, 1991, p.7 e 29.

12. W. Olins, idem, p.29.

13. W. Olins, idem, p.154.

14. M. Thévenet, Audit de la culture d'entreprise, p. 25.

15. Anika Michalowska, "Les baromètres», Autrement, n. ${ }^{\circ} 100,1988$, p. 35.

16. Emmanuel Alexandre, Créez vos publications d'entreprise, Paris, A. Colin, 1991.

17. Em boa hora, foi há pouco constituída a «APOREM - Associação Portuguesa de Empresas com Museu», que, de 18 de Maio a 18 de Junho de 1992, organizou, em Lisboa, o 1. Salão de Museus de Empresa.

18. W. Olins, Identité d'entreprise, p. 215.

\section{BIBLIOGRAFIA}

ALEXANDRE , Emmanuel, 1991, Créez vos publications d'entreprise, Paris, A. Colin.

BELTRAN, Alain e RUFFAT, Michèle, 1991, Culture d'entreprise et histoire, Paris, Les Éditions d'Organisation.

BOLLINGER, Daniel e HOFSTEDE, Geert, 1987, Les différences culturelles dans le management. Comment chaque pays gère-t-il ses hommes? Paris, Les Éditions d'Organisation.

FUMARIOLI, Marc, 1991, L'État culturel. Essai sur une religion moderne, Paris, Ed. Fallois.

GÉLINIER, Octave, 1990, Stratégie de l'entreprise et motivation des hommes, Paris, Les Éditions d'Organisation. 
«Gourou (Le). Entretien avec Tom Peters», 1988, Autrement, n. ${ }^{\circ} 100$, p. 49.

LARÇON, J. P. e REITER, R., 1979, Structures de pouvoir et identité d'entreprise, Paris, Ed. Fernand Nathan.

MENDES, José M. Amado (col. de Manuel Ferreira Rodrigues), 1992, Santos Barosa - 100 anos no vidro, 1889-1989, Marinha Grande, Santos Barosa - Vidros, S.A.

MICHALOWSKA, Anika, 1988, «Les baromètres», Autrement, n. ${ }^{\circ} 100$.

OLINS, Wally, 1991, Identité d'entreprise. Pour rendre la stratégie d'entreprise visible (trad. do inglês), Paris, Inter Éditions.

PETERS, Tom e AUSTIN, Nancy, 1988, A paixão pela excelência (trad. do inglês), Lisboa, Pensamento-Editores Livreiros.

RETO, Luís e LOPES, Albino, 1990, Identidade da empresa e gestão pela cultura, Lisboa, Ed. Sílabo.

SCHEIN, 1984, «Coming to a awareness of organizational culture», MIT, Sloan Management Review, Winter.

THÉVENET, Maurice, 1984, «La culture d'entreprise en neuf questions», Revue Française de Gestion, n. $^{\circ} 47-48$.

THÉVENET, Maurice, 1986, Audit de la culture d'entreprise, Paris, Les Éditions d'Organisation.

THÉVENET, Maurice, 1988, «Voyage d'un "entreprenaute" dans la tribu. Mode d'emploi à usage de diagnostic. Quels sont les outils d'identification d'une culture d'entreprise?", Autrement, $\mathrm{n} .{ }^{\circ} 100$.

«Ticket-choc (Le) de la culture d'entreprise», 1988, Autrement, n. ${ }^{\circ} 100$. 